\title{
CARACTERIZAÇÃO MORFOLÓGICA DOS SOLOS DE QUINTAL AGROFLORESTAL, FLORESTA SECUNDÁRIA E CULTIVO DE MARACUJÁ (Passiflora edulis) NO ASSENTAMENTO ALEGRIA, SUDESTE DO PARÁ
}

\author{
Eguinaldo dos Santos Guimarães ${ }^{1}$; Camila Lima Santos²; Lenon José de Azevedo \\ Silva ${ }^{3}$; Andrea Hentz de Mello ${ }^{4}$. \\ ${ }^{1}$ Graduando do curso de Agronomia da Faculdade de Ciências Agrárias de Marabá (FCAM), Universidade \\ Federal do Pará (UFPA). Marabá, Pará, Brasil. eguinaldoguimaraes@ gmail.com \\ ${ }^{2}$ Graduando do curso de Agronomia da FCAM, UFPA. Marabá, Pará, Brasil. camila.lima45@ hotmail.com \\ ${ }^{3}$ Graduando do curso de Agronomia da FCAM, UFPA. Marabá, Pará, Brasil.aqui.tec@ hotmail.com \\ ${ }^{4}$ Professora, Doutora da FCAM, UFPA. Marabá, Pará, Brasil. andreahentz@ufpa.com.
}

\begin{abstract}
RESUMO: O estudo dos solos é de extrema importância, sendo a caracterização morfológica destes um importante subsídio de entendimento para a aplicação de tecnologias para a produção agrícola. Assim, buscou-se, por meio da caracterização dos solos de três agroecossistemas, explicitar as diferenças e similaridades nos três diferentes perfis do solo, além de buscar relacionar as características aos diversos usos da terra, buscando sempre entender a origem da fertilidade dos solos. A pesquisa foi realizada em novembro de 2012, no projeto de assentamento Alegria, localizado no município de Marabá no Sudeste do Pará. Foram abertos três perfis no solo, um em cada agroecossistema, no cultivo de maracujá (Passiflora edulis Sims), o perfil I, mediu cerca de $115 \mathrm{~cm}$, na floresta secundária o perfil mediu $130 \mathrm{~cm}$ e no quintal agroflorestal o perfil mediu $105 \mathrm{~cm}$, todos com três camadas bem definidas. Assim, foram caracterizadas, em cada perfil, a cor, textura, estrutura, cerosidade, porosidade, consistência e plasticidade. No geral, os solos apresentaram características morfológicas semelhantes e fertilidade preservada, sendo que a primeira seção de cada perfil apresenta horizonte orgânico e a terceira seção se configurou um horizonte B textural, classificando os solos como Argissolos.
\end{abstract}

PALAVRAS-CHAVES: agroecossistemas, classificação dos solos, matéria orgânica.

\section{SOIL MORPHOLOGICAL CHARACTERIZATION OF HOMEGARDENS, SECONDARY FOREST AND A GROWING PASSION FRUIT (Passiflora edulis), IN SETTLEMENT JOY, SOUTHEAST PARÁ}

\begin{abstract}
The study of soils is of utmost importance, and the morphological characterization of such an important allowance for understanding the application of technologies for agricultural production. Thus, we sought, through the characterization of soils of three ecosystems, explain the differences and similarities in the three different soil profiles, and seek to relate the characteristics of the various land uses, always seeking to understand the origin of soil fertility. The survey was conducted in november 2012, the settlement project Alegria, located in the municipality of Maraba in Southeastern Pará were opened three profiles on the ground, one in agroecosystems, the cultivation of passion fruit (Passiflora edulis Sims), the profile I measured about $115 \mathrm{~cm}$ in secondary forest profile measured $130 \mathrm{~cm}$ and in the backyard agroforestry profile measured $105 \mathrm{~cm}$, all with three well defined layers. Therefore, we characterized, in each profile, color, texture, structure, waxy, porosity, texture and plasticity. In general, soils showed similar morphological
\end{abstract}


characteristics and fertility preserved, and the first section of each profile presents horizon organic and the third section configured a textural B horizon, classifying soils as Ultisols.

KEY-WORDS: agroecosystems, classification of soil, organic matter.

O estudo da morfologia do solo é extremamente importante, uma vez que através dele se faz o julgamento dos diversos aspectos morfológicos visando à classificação do solo para posterior aproveitamento dos conhecimentos nas práticas agrícolas e estudo de gênese (PRADO, 1991).

Para caracterização do solo deve-se observar a cor, que avalia características importantes; a textura, que está relacionada às frações granulométricas presente no mesmo; a estrutura, que avalia o arranjamento das partículas; a porosidade, que são os espaços existentes entre as partículas sólidas e os agregados do solo; e a consistência, que esta relacionada à sua plasticidade (SILVA, 2010a).

Assim, o objetivo deste trabalho foi caracterizar morfologicamente os solos de três agroecossistemas, sendo um quintal agroflorestal, um cultivo de maracujá e floresta secundária, além de investigar a origem da fertilidade dos solos.

Este trabalho foi realizado no assentamento Alegria no município de Marabá, localizado no Sudeste Paraense, durante o estágio de campo obrigatório do curso de Agronomia da Faculdade de Ciências Agrárias de Marabá.

Segundo Köppen o clima da região é classificado como Tropical Chuvoso de Selva Isotérmico (Afi), com temperatura média de $28{ }^{\circ} \mathrm{C}$ e precipitação média anual de 1925,7 mm/ano (ALMEIDA, 2007).

O relevo do assentamento é plano a levemente ondulado e o lote possui relevo predominantemente plano, sendo o tamanho da propriedade uma área de 30 hectares.

O estudo foi relizado em um quintal agroflorestal, em um cultivo de maracujá (Passiflora edulis Sims) e em uma área de floresta secundária. Foram abertos três perfis no solo, um em cada agroecossistema.

Os perfis foram abertos manualmente com a utilização de enxadas, cavador e pá, todos com largura de aproximadamente 80 $\mathrm{cm}$. Após a escavação foram demacadas as camadas do perfil para a caracterização, por meio do manual de Lemos et al. (2009) da cor, textura, estrutura, cerosidade, porosidade, consistência e plasticidade de cada seção.

Os dados foram processados e apresentados através da descrição 
morfológica dos solos através de quadros e figuras.

O perfil I (Quadro 1), situado no cultivo de maracujá, mediu cerca de 115 $\mathrm{cm}$, sendo a primeira seção orgânica com
$19 \mathrm{~cm}$ e a terceira seção com $65 \mathrm{~cm}$ com predominância de horizonte com excesso de argila com transição abrupta, configurando-se como um horizonte B textural.

Quadro 1. Caracterização morfológica do solo com três seções em um cultivo de maracujá (Passiflora edulis) (Perfil I). Assentamento Alegria - Marabá - PA.

\begin{tabular}{|l|l|l|l|}
\hline CARACTERÍSTICAS & SEÇÃO I & SEÇÃO II & SEÇÃO III \\
\hline COR & Bruno-acizentado & Amarelo-claro-acinzentado & Amarelo \\
\hline TEXTURA & Franco arenosa & Franco argilo arenosa & Muito argilosa \\
\hline ESTRUTURA & Granular & Blocos subangulares & Blocos subangulares \\
\hline CEROSIDADE & Sem cerosidade & Sem cerosidade aparente & Sem cerosidade \\
\hline CONSISTÊNCIA SECA & Ligeiramente dura & Dura & Muito dura \\
\hline CONSISTÊNCIA ÚMIDA & Friável & Friável & Muito friável \\
\hline PLASTICIDADE & Ligeiramente plástica & Plástica & Muito plástica \\
\hline PEGAJOSIDADE & Ligeiramente pegajosa & Ligeiramente pegajosa & Pegajosa \\
\hline
\end{tabular}

Neste agroecossistema, a presença de matéria orgânica na seção I é marcante devido a incorporação de material vegetal no solo durante o período de cultivo. Diante disto, o bom manejo do agroecossistema pode ser o responsável por essa disponibilidade de nutrientes na área, pois com ele se mantém a cobertura do solo com adventícias, executando apenas o roço sem nenhuma aplicação de herbicida ou queima da biomassa das plantas invasoras.

A execução do plantio direto da cultura de maracujá também contribui bastante para essa disponibilidade das bases. Segundo Santos e Tomm (1996) o plantio direto promove alterações das propriedades químicas do solo e melhora a eficiência do uso de nutrientes pelas plantas. Estas alterações são destacadas pelo acúmulo de matéria orgânica e de nutrientes na camada superficial dos solos (SILVEIRA; CUNHA, 2002).

A segunda seção constitui-se como de transição. $\mathrm{Na}$ terceira seção a textura compreendeu $70 \%$ de argila e $30 \%$ areia, ou seja, mudança de $100 \%$ em relação aos mesmos elementos da primeira seção. Pela extensão dessa última seção, além das outras características verificadas, se caracterizou essa seção como um horizonte B textural, e consequentemente o solo como um Argissolo. 
$\mathrm{Na}$ área de Floresta secundária, a caracterização morfológica do perfil II, apresenta uma série de parâmetros morfológicos que corroboram com os do perfil I, como demonstrado no Quadro 2.

Quadro 2. Caracterização morfológica do solo com três seções em uma área de Floresta secundária (Perfil II). PA Alegria - Marabá-PA.

\begin{tabular}{|l|l|l|l|}
\hline CARACTERÍSTICAS & SEÇÃO I & SEÇÃO II & SEÇÃO III \\
\hline COR & Bruno-acizentado & Amarelo-claro-acinzentado & Amarelo \\
\hline TEXTURA & Franco Argilo Arenosa & Argilo arenosa & Muito argilosa \\
\hline ESTRUTURA & Granular & Blocos subangulares & Blocos subangulares \\
\hline CEROSIDADE & Sem cerosidade & Sem cerosidade & Sem cerosidade \\
\hline CONSISTÊNCIA SECA & Ligeiramente dura & Dura & Muito dura \\
\hline CONSISTÊNCIA ÚMIDA & Friável & Friável & Firme \\
\hline PLASTICIDADE & Plástica & Plástica & Muito plástica \\
\hline PEGAJOSIDADE & Ligeiramente pegajosa & Pegajosa & Pegajosa \\
\hline
\end{tabular}

Nesse agroecossistema de floresta secundária o solo encontra-se muito intemperizado e profundo, com textura de aproximadamente $70 \%$ de areia na primeira seção e $80 \%$ de argila na seção III. Importante ressaltar que esse agroecossistema caracteriza-se como um ecossistema natural, logo o solo se mantêm em constante evolução quanto aos processos biogeoquímicos. Houve ainda abundância de matéria orgânica, sendo a serrapilheira uma importante fonte para a renovação desses recursos no agroecossistema.

O quintal agroflorestal foi, dentre os agroecossistemas estudados, o que apresentou textura mais arenosa na sua primeira seção que medindo $26 \mathrm{~cm}$ caracterizou-se por uma grande quantidade de matéria orgânica, evidenciada pela classificação da cor, conforme descrição no Quadro 3.

Quadro 3. Caracterização morfológica do solo com três seções em um quintal agroflorestal (Perfil III).PA Alegria - Marabá - PA.

\begin{tabular}{|l|l|l|l|}
\hline CARACTERÍSTICAS & SEÇÃO I & SEÇÃO II & SEÇÃO III \\
\hline COR & Bruno-acizentado-escuro & Amarelo-claro-acinzentado & Amarelo \\
\hline TEXTURA & Argilo Franco Arenosa & Argilo arenosa & Argila \\
\hline ESTRUTURA & Granular & Granular & Blocos subangulares \\
\hline CEROSIDADE & Sem cerosidade & Sem cerosidade & Sem cerosidade \\
\hline CONSISTÊNCIA SECA & Macia & Ligeiramente Dura & Ligeiramente dura \\
\hline CONSISTÊNCIA ÚMIDA & Friável & Firme & Friável \\
\hline PLASTICIDADE & Não Plástica & Plástica & Plástica \\
\hline PEGAJOSIDADE & Não pegajosa & Ligeiramente Pegajosa & Pegajosa \\
\hline
\end{tabular}


A textura média deste perfil apresentou cerca de $80 \%$ de areia e apenas $20 \%$ de argila. No entanto, a matéria orgânica contribui para a estruturação e cimentação do solo.

Assim, mesmo sendo diferente o uso do solo em cada agroecossistema a conservação das propriedades físicas e químicas destes se mantêm em equilíbrio, graças ao uso sustentável do solo, logo, a junção dos conhecimentos do agricultor e os estudos edáficos, são de extrema importância para que se tenha êxito na consolidação da agricultura no estabelecimento agrícola familiar.

Por fim, conclui-se que nos três diferentes sistemas os solos estudados caracterizaram-se como Argissolo e o manejo dos agroecossistemas está sendo realizado de forma sustentável.

\section{REFERÊNCIAS}

ALMEIDA, M. F. Caracterização agrometeorológica do município de Marabá/PA, Marabá, 2008. 77 f. Trabalho de Conclusão de Curso (Graduação em Agronomia)- Universidade Federal do Pará, Colegiado de Ciências Agrárias, Marabá, 2007.

LEMOS, R. C.; SANTOS, R. D.; SANTOS, H. G.; KER. J.; ANJOS. L. H. C. Manual de descrição e coleta de solo no campo. Campinas: Sociedade Brasileira de Ciência do Solo/SNLCS, 2005. 91p.

PRADO, H. Manejo dos Solos- aspectos pedológicos e suas implicações. Primeira. ed. São Paulo:Nobel, 1991. 116 p.

SANTOS, H. P.; TOMM, G.O. Estudo da fertilidade do solo sob quatro sistemas de rotação de culturas envolvendo trigo em plantio direto. Revista Brasileira Ciências do Solo, Campinas, v.20, p. 407-414, 1996.

SILVA, F. A. M.; ANJOS, L. N. C. dos; SANTOS, K. O. dos; SILVA, E. M. da ; SILVA, S. A. S. da; Caracterização morfológica dos solos em três propriedades rurais, no travessão das 6 e 8 no município de Brasil Novo - PA, 2010. In: Semana de Integração das Ciências Agrárias, 10. Altamira- PA. Anais... Altamira: SICA, 2010.

SILVEIRA, P.; CUNHA, A. A. Variabilidade de micronutrientes, matéria orgânica e argila de um Latossolo submetido a sistemas de preparo. Pesquisa Agropecuária. Brasileira, Brasília, v.37, p.1325-1332, 2002. 